\title{
Passive-Sampler-Based Bioavailability Assessment of PCB Congeners Associated With Aroclor- containing Paint Chips in the Presence of Sediment
}

Guilherme Lotufo ( $\nabla$ guilherme.lotufo@usace.army.mil )

US Army Engineer Research and Development Center https://orcid.org/0000-0002-1640-1752

Philip Gidley

US Army Engineer Research and Development Center

Andrew McQueen

US Army Engineer Research and Development Center

David Moore

US Army Engineer Research and Development Center

Deborah Edwards

ExxonMobil Research and Engineering Company: ExxonMobil Corp

Jeffery Hardenstine

Newfields Environmental Forensics Practice LLC: NewFields

Allen Uhler

Newfields Environmental Forensics Practice LLC: NewFields

\section{Research Article}

Keywords: PCBs, paint, bioavailability, sediment, polymer-sediment accumulation factor

Posted Date: July 20th, 2021

DOl: https://doi.org/10.21203/rs.3.rs-715786/v1

License: (c) (i) This work is licensed under a Creative Commons Attribution 4.0 International License.

Read Full License

Version of Record: A version of this preprint was published at Archives of Environmental Contamination and Toxicology on December 17th, 2021. See the published version at https://doi.org/10.1007/s00244021-00907-2. 


\section{Abstract}

This is the first investigation of the bioavailability of PCBs associated with paint chips (PC) dispersed in sediment. Bioavailability of PCB-containing PC in sediment was measured using ex situ polyethylene passive samplers (PS) and compared to that of PCBs from field-collected sediments. PC were mixed in freshwater sediment from a site with no known PCB contamination sources and from a contaminated site with non-paint PCB sources. Particles $<0.045 \mathrm{~mm}$ generated concentrations in the PS over one order of magnitude higher than coarser particles. The bioavailable fraction was represented by the polymersediment accumulation factor (PSAF), defined as the ratio of the PCB concentrations in the PS and organic carbon normalized sediment. The PSAF was similar for both field sediments and was $\sim 50-60$ and $\sim 5$ times higher than for the $0.25-0.3 \mathrm{~mm}$ and $<0.045 \mathrm{~mm}$ fractions, respectively, of PC mixed in sediment. These results indicate much lower bioavailability for PCBs associated with PC compared to PCBs associated with field-collected sediment. Such information is essential for risk assessment and remediation decision making for sites where contamination from non-paint PCBs sources are co-located with PCB PC.

\section{Introduction}

PCBs are a class of synthetic chlorinated organic compounds that, due to their chemical and physical stability, were manufactured in the United Sates under the trade name "Aroclor" between 1929 and 1977 (Miller 1983). Historically, Aroclor mixtures were primarily used in electrical equipment (Miller 1983) but were also widely used as plasticizers within construction materials, including an additive to paint and surface coatings. Chemical-resistant chlorinated rubber paints contained various Aroclors typically at 10$12 \%$ (dry weight) of the total composition (Scott and Snyder 2015). Construction materials containing PCBs were widely used in industrial and institutional settings (Scott and Snyder 2015; Jartun et al. 2009), but also in construction and maintenance of military and civilian vessels. PCBs were added to ship paints to give the paints better adhesive properties and to provide protection from corrosion, chemicals and flames (Jensen et al. 1972; Martin and Richards 2010). Aroclor 1254 was the most common plasticizer added to paints through the early 1970s (Scott and Snyder 2015). Additional information on the history use of PCB-containing paint is provided in the Supplementary Information.

Vessel maintenance activities, including power washing of vessels and removal of old paint (including paints containing PCBs) via sand blasting have been identified as a source of PCB contamination in aquatic environments (Jensen et al. 1972; Johnsen and Engøy 2000; Gold and Bloom 2000; Martin and Richards 2010; Bellucci et al. 2016; Oregon Department of Environmental Quality 2020). For example, release of paint residues from ship repair yards and direct release from the hull during port calls were responsible for a considerable fraction of contaminants, including PCBs, associated with sediments outside of ship repair yards and around quay structures in Norway (Johnson and Engøy 2000). In addition to vessel paint, PCB-containing paint from buildings and other structures were found to be the source of PCB contamination of aquatic (Russ et al. 2006; Jartun et al. 2009) and terrestrial environments (Andersen et al. 2000; Martin and Richards 2010). Bioaccumulation of PCBs in aquatic 
biota has been attributed environmental contamination to PCB-containing paint (Jensen et al. 1972; Russ et al. 2006). Additional information on the environmental contamination by PCB-containing paint contamination, including concentrations reported for biota, sediment and soil at impacted sites are provided in the Supplementary Information. Regardless of the evidence for the unintended release of PCB-containing paint chips into aquatic environments, there are no published studies regarding the fate and behavior (e.g., leaching studies), bioavailability potential, or potential for benthic bioaccumulation for paint-associated PCBs.

Bulk sediment chemical concentrations $\left(C_{\text {total }}\right)$ have historically been used in contaminated sediment site characterization, risk assessment, and risk management (Greenberg et al. 2014). However, risk assessments, and consequently risk management decisions and actions carry a relatively high level of uncertainty without an understanding of bioavailability. Passive samplers (PSs) of various types have been used as tools to directly sample porewater dissolved hydrophobic organic compounds (HOCs) and reliably estimate freely dissolved concentrations $\left(\mathrm{C}_{\text {free }}\right)$ in water or porewater, which in turn has been shown to be a good thermodynamic metric for bioavailability assessment (Adams et al. 2007; Gschwend et al. 2011; Booij et al. 2016; Smedes et al. 2017; Beckingham and Ghosh 2017; Endo et al. 2020). Passive sampler hydrophobic organic compound (HOC) uptake has also been used as a surrogate for whole-body bioaccumulation in aquatic organisms, in both laboratory and field exposures, as reviewed in Joyce et al. (2016) and Schmidt and Burgess (2020). Therefore, the use of $C_{\text {free }}$ instead of bulk chemical analyses ensures more certainty for contaminated sediment assessment and risk management.

PCBs are released to the environment as a result of industrial process such as burning of coal and wood, incineration, leaks from machinery, damaged heat exchangers and transformers, and enter the aquatic environment from wastewater, stormwater, combined sewer overflows and atmospheric deposition (Wolska et al. 2014; Du et al. 2008). Due to their hydrophobic nature, PCBs entering aquatic environments strongly adsorb to suspended and bottom sediments. In most contaminated sites, the source of PCBs is not co-located with the contaminated sediment. For example, wastewater containing PCBs was historically discharged into the Hudson River (NY, USA) from capacitor manufacturing facilities. At other contaminated sites, materials containing PCBs such as paint, plaster, caulk remain dispersed in sediment or soil (Andersson et al. 2004; Russ et al. 2006; Herrick et al. 2007; Martin and Richards 2010; Davies and Delistraty 2016). For sites where PCB-containing manufactured materials such as PCB-containing paint chips $(P C)$ are present, sediment is typically contaminated with PCBs from other sources, such as off-site input. Therefore, understanding the bioavailability for PCBs associated with PC relative to the bioavailability of native sediment PCBs (i.e., differential bioavailability) is greatly desirable.

The primary objective of this study was to test the hypothesis of no difference in bioavailability between PCBs associated with PC dispersed in sediments and PCBs associated with field-collected sediments historically contaminated by sources other than paint. Differential bioavailability assessment provides a relative scaling of the tendency for contaminants associated with different environmental media (e.g., different types of organic matter or different manufactured materials), to be strongly sequestered, or quickly released and accumulated by organisms (Beckingham and Ghosh 2017). Investigation of 
differential bioavailability is facilitated by the use of PS (a uniform phase) which provide bioavailability measurements without the need to account for complex partitioning to a multitude of matrices contained in sediments.

\section{Materials And Methods}

\section{PCB-containing paint used in the bioavailability evaluation}

The chlorinated rubber marine base paint used in this bioavailability experiment, prepared as described in Uhler et al. (2021), was made up to a concentration of approximately $2 \%$ Aroclor 1254 (w/w, liquid), which is equivalent to $4 \%$ Aroclor 1254 on a dry paint basis. This $2 \%$ formulation was used in order to optimize the concentration of PCB in sediment with a maximum density (mass and number) of PC, thereby improving PC homogeneity among experimental sediment treatments. The formulated paint was applied to a steel panel, dynamically aged in seawater for one month following methods described in Kojima et al. (2016), air-dried, and removed using a razor blade (Uhler et al. 2021).

\section{Preparation of paint chip size classes}

Flakes of PCB-containing paint were ground using a mortar and pestle and dry sieved using stainless steel sieves to achieve 3 separate PC size classes ("coarse" = 2-5 mm; ASTM \#10; "medium" = 0.2500.300 mm; ASTM \#50-60; "fine" = <0.045 mm; ASTM \#325; Figure S1). Following grinding, the particles were stored in amber glass jars at $4{ }^{\circ} \mathrm{C}$ prior to addition to sediment for experimental purposes.

Due to the role of surface area in chemical reactivity (e.g., sorption and desorption), both specific surface area and surface-area-to-volume ratios were calculated for the three size classes of PC. For the "coarse" PC, the specific surface area $\left(\mathrm{cm}^{2} / \mathrm{g}\right)$ was estimated based on the geometry of a flat (plate-like) structure (Equation 1; Pennel 2016).

\section{Specific surface area $($ flat stucture $)=(2 a b) /(\rho V)$ (Eq. 1)}

Where $\rho$ is the density of PC ( $\nabla 2.8 \mathrm{~g} / \mathrm{cm}^{3}$ for dry $4 \%$ Aroclor $\left.1254 \mathrm{PC}\right), a$ is the length, $b$ is the width, and $V$ is the volume (i.e., length $(a)^{*}$ width $(b)^{\star}$ height $\left.(c)\right)$ of the structure. Length $(a)$ and width $(b)$ estimates were based on sieve diameter sizes. The average thickness $(c)$ of the dried PC was approximately 0.078 $\mathrm{mm}$.

For the ground PC medium and fine size classes, the particle shape was assumed to approximate a sphere, where the specific surface area $\left(\mathrm{cm}^{2} / \mathrm{g}\right)$ was estimated using Equation 2 (Pennel 2016).

$$
\text { Specific surface area }(\text { sphere })=3 /(\rho r) \quad \text { (Eq. 2) }
$$

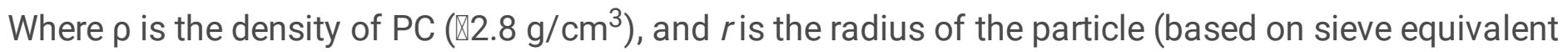
diameter sizes). 
Estimates of surface-area-to-volume (S:V) ratios were $1,333, \varangle 220$, and $₫ 250$ for the fine, medium and coarse fractions, respectively (Table 1). It should be noted that these values are estimates as they do not account for surface texture, non-spherical particles, or finer particles that may be present (Pennel 2016).

Table 1. Specific surface area and S:V estimations for paint particles.

\begin{tabular}{|c|c|c|c|}
\hline Size Class & Diameter (mm) & Estimated Specific Surface Area ${ }^{a}\left(\mathrm{~cm}^{2} / \mathrm{g}\right)$ & S:V \\
\hline Coarse & $2-5$ & $92^{\mathrm{a}}$ & $256^{c}$ \\
\hline Medium & $0.25-0.3$ & $71-86^{b}$ & $200-240^{d}$ \\
\hline Fine & 0.045 & $476^{\mathrm{b}}$ & $1,333^{d}$ \\
\hline
\end{tabular}

Sediment with very low levels of PCBs was collected from a single location at Horseshoe Lake (HSL) an oxbow lake alongside the Mississippi River (Warren County, MS), with no known sources of PCBs. The HSL sediment was comprised of $34.2 \%$ solids, with a predominance of fine particles and OC content of $3.6 \%$. The sediment was thoroughly homogenized with a propeller mixer (Lightnin® Vari-Mix portable mixer; Mixing Equipment) and stored at $4{ }^{\circ} \mathrm{C}$ in clean polyurethane buckets before use. The concentration of $\sum$ PCBs (sum of 33 detected congeners) was $0.013 \mathrm{mg} / \mathrm{kg}$ dry wt.

Sediment contaminated with relatively high concentration of PCBs was collected from several locations in the Manistique Harbor (MH) Superfund site located in Manistique, Michigan on the southern shore of Michigan's Upper Peninsula. The primary sources of contamination at this site include release of PCBs from former paper mill and lumber mill operations, discharge from area industrial facilities and nonpoint sources. Fish collected at the site have elevated levels of PCBs, indicating bioavailability and bioaccumulation of contaminants from the sediment (Gustavson 2014). The field-collected sediments were thoroughly homogenized with a propeller mixer and stored at $4{ }^{\circ} \mathrm{C}$ in clean polyurethane buckets before use. $\mathrm{MH}$ sediment was comprised of $35 \%$ solids, with a predominance of fine particles. The average concentration of $\sum$ PCBs sum of 171 detected congeners) and OC content, based on sediments obtained from replicate jars after non-depletive ex situ passive sampling, were $5.84 \pm 1.78 \mathrm{mg} / \mathrm{kg}$ and 6.7 $\pm 0.3 \%$. The relatively low variability for PCB concentration and OC content across replicates indicate that sediment was adequately homogenized.

\section{Ex situ passive sampling}

Each PS consisted of a $2.5 \mathrm{~cm}$ X $6 \mathrm{~cm}(\sim 25 \mathrm{mg})$ PE $(17.2 \mu \mathrm{m}$ thick, HDXTM brand) coupon. The PSs were cleaned by soaking at least three times in dichloromethane (DCM). Each soaking lasted 2 to 3 days. Clean DCM was used for each cleaning cycle. The PS were then rinsed with water multiple times, each for 
a period of days. Each time clean Milli-Q water was used. The PSs were stored in water (sealed in a jar) for approximately 8 weeks prior to use.

Sediment was portioned into approximately half-liter glass jars (16-oz) with Teflon lined caps. One PS was then added to each jar. PC were then added to create mixtures of sediment, PC and one PS. Each mixture was a fluid slurry and at least $25 \%$ of the volume of the jar was left as headspace. Hand shaking of the jars confirmed that the slurries would move inside the jars during mixing. The jars were rotated endover-end at 30 revolutions per minute (rpm) most of the time. However, initially not all jars could fit on the end-over-end mixer, so some jars were placed on a slower mixer at $5 \mathrm{rpm}$ (end-over-end). The jars were rotated across mixers, so that all jars spent at least two thirds of their mixing time at $30 \mathrm{rpm}$. Rotation was accomplished by removing jars from the mixers, hand shaking the jars, and placing them back on the mixers in different locations/configurations. The aim was to promote and maximize a well-mixed slurry environment in the jars for the longest time possible within the timeframe of the project. At the termination of the mixing period, PSs were retrieved from the jars using tweezers. The coupons were rinsed with deionized water and wiped with a lint-free paper tissue to remove sediment particles from the surface of the PS. The PSs were individually tightly wrapped in aluminum foil. Each wrapped PS was placed in a 40-mL amber glass vials with Teflon lids. A few drops of water were placed in the vials to maintain moisture (Apell and Gschwend 2016) to lessen loss of PCBs from the PS. The vials along with the sediment recovered from each jar were shipped on ice overnight to Alpha Analytical Laboratory (Mansfield, MA, USA) for PCB analysis.

\section{Bioavailability of paint-associated PCBs in the presence of sediment: Effect of paint chip particle size}

To evaluate the effect of particle size on bioavailability, four ex situ passive sampling jars were set up for each PC size class. Each jar received $241.5 \pm 0.2 \mathrm{~g}$ wet weight of the HSL sediment corresponding to $83 \mathrm{~g}$ of dry sediment, one PS and $10 \pm 0.1 \mathrm{mg}$ of PC targeting $4 \mathrm{mg} / \mathrm{kg} \sum \mathrm{PCBs}$ as PC to create the class size treatments $\mathrm{HSL}+\mathrm{PC}_{\mathrm{FINE}}, \mathrm{HSL}+\mathrm{PC}_{\mathrm{MEDIUM}}$, and $\mathrm{HSL}+\mathrm{PC}_{\mathrm{COARSE}}$. This concentration was selected to match the $\sum \mathrm{PCBs}$ concentration in the MH sediment according to historic data and was approximately 4 times higher than high-end concentrations reported for sites impacted by PCB-containing paint (Supplementary Information). For $\sum$ PCBs in the bulk sediment, the concentration of PC PCBs exceeded the concentration of native PCBs the sediment by 308 -fold. The contents of the jars (sediment, PC, and PS) were mixed for $60 \mathrm{~d}$ to allow for PCB redistribution between PC, sediment and PS. A time period of $60 \mathrm{~d}$ was previously reported as sufficient time for sediment-associated PCBs to attain thermodynamic equilibrium with 25$\mu \mathrm{m}$ PS during ex situ passive sampling (Lohman et al. 2012; Apell and Gschwend 2016). To verify if equilibrium of PCBs was achieved between sediment and PC, and PS, additional jars were set up as

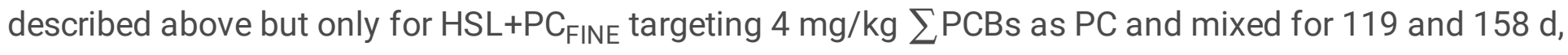
four jars per time point. Even though the concentrations of native PCBs in HSL sediment were low, they were above detection limit for 33 congeners. Therefore, HSL sediment without added PC were also evaluated for bioavailability using PS as described above. 


\section{Bioavailability evaluation using an historically contaminated sediment amended with paint chips}

For this component of the investigation, two treatments for ex situ passive sampling with PE PS were setup as described above: 1) $\mathrm{MH}$ sediment only, and 2) MH sediment and the fine PC fraction combined $\left(\mathrm{MH}+\mathrm{PC}_{\mathrm{FINE}}\right)$. The primary goal was to conduct a bioavailability comparison for paint-associated PCBs and sediment-associated PCBs. Because some of the PCBs in MH were not present in PC, we also investigated whether PC would serve as a sorptive matrix for sediment-associated PCBs, reducing bioavailability of congeners not initially present in the PC.

For this experiment, each jar received $268 \pm 0.2 \mathrm{~g}$ wet weight $\mathrm{MH}$ sediment corresponding to $92 \mathrm{~g}$ of dry

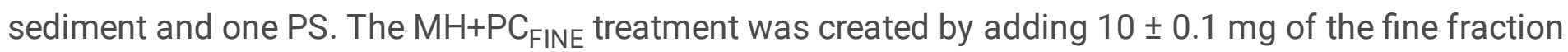
of PC to $\mathrm{MH}$ sediment targeting $4 \mathrm{mg} / \mathrm{kg} \sum \mathrm{PCBs}$ as $\mathrm{PC}$ (target total PCBs concentration $=9.8 \mathrm{mg} / \mathrm{kg}$ dry wt.). Four jars were set up for each treatment and the contents of the jars (sediment, PC, and PS) were mixed for $60 \mathrm{~d}$. The average concentration of $\sum$ PCBs (sum of 180 detected congeners) for the $\mathrm{MH}+\mathrm{PC}_{\mathrm{FINE}}$ treatment, based on sediments obtained from replicate jars after ex situ passive sampling, was $8.25 \pm 0.74 \mathrm{mg} / \mathrm{kg}$.

\section{Chemical analysis}

Sediment extraction. Approximately $20 \mathrm{~g}$ of well homogenized sediment was weighed into a Teflon ${ }^{\text {TM }}$ extraction jar, dried with sodium sulfate, fortified with surrogate compounds, and serially extracted three times with DCM using an end-over-end mixer. Extracts were filtered through glass wool containing sodium sulfate and concentrated on a hot water bath. Extracts were cleaned with activated copper to remove sulfur and processed through a silica gel column followed by high pressure liquid chromatography (HPLC) containing a size exclusion gel permeation column (GPC). Extracts were solvent exchanged into hexane and acid cleaned using sulfuric acid.

PS extraction. Each PS was placed into a $250 \mathrm{~mL}$ amber glass jar equipped with a Teflon ${ }^{\mathrm{TM}}$ liner, dried with sodium sulfate, fortified with surrogate compounds, and serially extracted three times with DCM using a shaker table. Extracts were filtered through glass wool containing sodium sulfate and concentrated on a hot water bath. Extracts were cleaned with activated copper to remove sulfur, solvent exchanged into hexane and acid cleaned using sulfuric acid.

Instrumental analysis. All extracts were fortified with an internal standard and analyzed using an Agilent HP6890 or equivalent equipped with a Restek RTX-PCB 60-m x 0.18 mm ID, 0.18 um film thickness, fusedsilica capillary column and a mass spectrometer operated in the selected ion monitoring mode (SIM). The concentrations of the individual congeners were quantified versus internal (i.e., injection standards) standards, which were spiked into the sample extract prior to analysis. The target congener concentrations were quantified using average response factors generated from a minimum of a 6-point multi-level calibration curve. Sample extracts were analyzed for 209 PCB congeners using USEPA Method 680. 
Total Organic Carbon (TOC). Approximately $10 \mathrm{mg}$ of sample (pre-treated with $10 \%$ hydrochloric acid, dried, and homogenized) was weighed into a tin capsule, and analyzed using a CHNS/O Analyzer for TOC per USEPA 9060. All analysis was performed in duplicate and the average TOC value reported.

\section{Quality Control}

A series of quality control samples were included to monitor laboratory contamination, extraction efficiency, and reproducibility. This was accomplished through the use of procedural blanks, lab control samples/duplicates (LCS/LCSD), surrogates, lab duplicates, and National Institute of Standard Reference Material (NIST SRM).

No analyte was detected in the procedural blanks above the reporting limit. All laboratory spiked surrogates and LCS compounds met data quality objective (DQO) recoveries (50-125\% and $40-140 \%$ respectively). The lab duplicates had a relative percent difference (RPD) $<30 \%$ for over $90 \%$ of the analytes detected above the reporting limit and the NIST SRMs met the lab DQO recoveries (40-140\%) for all certified analytes detected above the reporting limit (see supplemental information).Detailed information on quality control and quality assurance is provided in the Supplementary Information.

\section{Data analysis}

Statistical comparisons were performed using SigmaStat v3.5 software (SSPS, Chicago, IL, USA). Normality was confirmed by the Shapiro-Wilk test and equal variance was confirmed using the BrownForsythe test. One-way ANOVA were performed to determine statistically significant differences $(a=$ 0.05 ) across three or more treatments. The Holm-Sidak method was employed for pairwise multiple comparisons to determine statistical significance between treatments. When assumptions of parametric ANOVA were not met, the data was log-transformed. The nonparametric Kruskal-Wallis one-way ANOVA on ranks was applied when assumptions of parametric ANOVA were not met for log-transformed data. The Dunn's method was employed for pairwise multiple comparisons to determine statistical significance between treatments. The Student's t test was used to determine whether statistically significant differences existed between treatment groups $(a=0.05)$. When assumptions of parametric t test were not met, the nonparametric Mann-Whitney Rank Sum test was applied.

\section{Results}

\section{Bioavailability of paint-associated PCBs dispersed in HSL sediment}

The congener profile for solvent-extracted PC mechanically reduced to a size that would pass through a

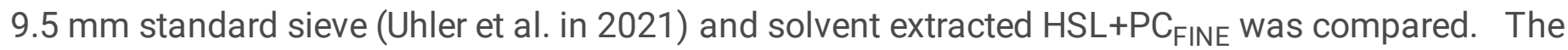
congener profile is presented here as the relative contribution of $\mathrm{PCB}$ congeners to the $\sum \mathrm{PCB}$ concentration, which was similar for a subsample of the PC used in this study and PC mixed with HSL sediment for $60 \mathrm{~d}$ (i.e., the HSL+PC $\mathrm{FINE}_{\text {INeatment) (Figure S2), with the ratio of PC and HSL+PC }}$ FINE ranging from 0.83 to 1.38 (average $=1.01$ ). This indicates that the mixing of PC with sediment did not 
cause significant changes in the relative concentration of the congeners. For Figure S2 and other figures showing congener data for HSL+PC treatments, a subset of analytes was selected for illustration of congener-specific trends in lieu of showing all data for congeners detected in sediment and PSs. The analytes shown in Figure S2 (and also in Figures 2, S3, S4 and S5) had a contribution to the total concentration in the PC of $0.5 \%$ or more. PCBs 84,89 and 92 were omitted because of analytical interferences on the chromatograms.

The $\sum$ PCBs concentration (sum of 161 detected congeners) for the HSL+PC treatments (averages $=3.0$,

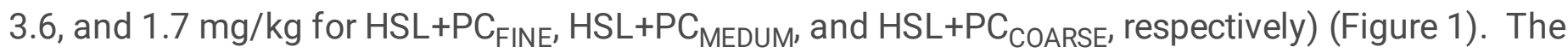
variability in the concentrations of $\triangle \mathrm{PCB}$ (Figure 1) and PCB congeners (Figure S3) in the PC sediment treatments was relatively low for $\mathrm{HSL}+P C_{\mathrm{FINE}}$ (coefficient of variation [CV] $=5 \%$ for $\sum \mathrm{PCB}$ and 4 to $13 \%$ for congeners) and HSL+PC MEDIUM $_{\text {( }}$ CV $=22 \%$ for $\sum \mathrm{PCB}$ and 17 to $24 \%$ for congeners) but much higher for HSL+PC COARSE $_{\text {( }}$ CV $=196 \%$ for $\sum P C B$ and 191 to $197 \%$ for congeners). The averaged concentration for HSL+PC COARSE $_{\text {was much lower than the target concentration and also lower than for HSL+PC }}$ FINE and $\mathrm{HSL}+\mathrm{PC}_{\text {MEDUM}}$. The lower than expected measured concentration and the high variability for the coarse PC is explained by the expected high heterogeneity for the distribution of PC in the sediment caused by the low density of PC for that size fraction. As a result, the concentration of PC for the whole jar was likely higher than the concentration measured in analytical subsamples.

The $\sum$ PCBs concentration for the HSL+PC treatments (averages $=3.0,3.6$, and $1.7 \mathrm{mg} / \mathrm{kg}$ for $\mathrm{HSL}+\mathrm{PC}_{\mathrm{FINE}}, \mathrm{HSL}+\mathrm{PC}_{\mathrm{MEDUM}}$, and $\mathrm{HSL}+\mathrm{PC}_{\text {COARSE}}$, respectively) were substantially higher than concentrations in the HSL sediment prior to addition of PC $(0.013 \mathrm{mg} / \mathrm{kg})$ (Figure 1). Therefore, amending HSL sediment with PC caused an increase in the average concentration of $\sum$ PCB of 231-, 277-,

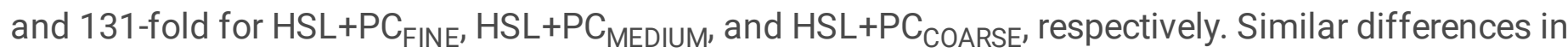
concentrations occurred for PCB congeners (Figure S3), and amendment with PC promoted increases from 33- to 585 -fold (average $=228 \pm 149$ ) for $\mathrm{HSL}+\mathrm{PC}_{\mathrm{FINE}}$, from 40- to 644-fold (average $=271 \pm 168$ ) for $\mathrm{HSL}+\mathrm{PC}_{\text {MEDIUM, }}$ and from 20 - to 258 -fold (average $=126 \pm 74$ ) for HSL+PC ${ }_{\text {COARSE. }}$ The mass contribution of native PCBs to the total mass of PCBs in the HSL + PC treatments was only approximately $0.5 \%$.

Despite the overall relative similarity in paint-associated PCB mass loading in the sediment for the PC size treatments, the concentrations in the PS depended on the PC size for both $\sum$ PCBs (Figure 1) and $\mathrm{PCB}$ congeners (Figure 2). Average concentrations in the PS for HSL+PC $\mathrm{FINE}_{\text {exceeded that for }}$ $\mathrm{HSL}+\mathrm{PC}_{\text {MEDIUM }}$ by 12 times for $\sum \mathrm{PCBs}$ and by 4 to 19 times (average $=11$ ) for the dominant congeners.

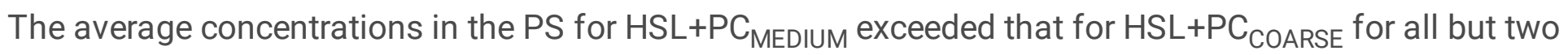
congeners, and the average exceedance was 1.3-fold.

The concentrations of PCBs congeners in the sediment and in PS differed widely between the HSL (no

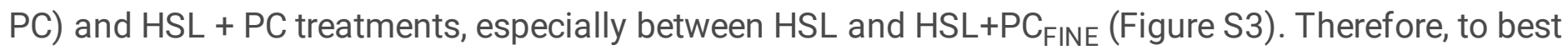
illustrate differences in bioavailability relative to bulk sediment concentrations between native PCBs in 
the HSL, and PCB-containing PC in HSL + PC treatments, concentrations in the PS were divided by the OCnormalized bulk concentration in the sediment treatment determined after exhaustive solvent extraction. This ratio is referred to as polymer-sediment accumulation factor (PSAF) and is well suited for illustrating differences in $\mathrm{C}_{\text {free }}$ among sediments with widely varying $\mathrm{C}_{\text {total }}$.

For the HSL sediment (no PC added), PSAF could only be calculated for congeners 52, 49, 121/95/68, $101 / 90,99,110,151,147 / 149,146,153,163 / 160$, and 180 which were detected in the sediment and in the PS (Figure 3). The PSAF values for HSL sediment were much higher than those determined for the $\mathrm{HSL}+\mathrm{PC}_{\mathrm{FINE}}$ and $\mathrm{HSL}+\mathrm{PC}_{\text {MEDIUM }}$ treatments (Figure 3). For the above congeners, the average PSAF for HSL $(0.67 \pm 0.23)$ was 5 times higher than the average for $H S L+P C_{F I N E}(0.13 \pm 0.02)$ and 62 times higher than the average for $\mathrm{HSL}+\mathrm{PC}_{\text {MEDIUM }}(0.012 \pm 0.007)$. Statistical analysis showed significant differences between treatments for all congeners except for congener 52 (Figure 3).

The bioavailability potential relative to bulk concentration of PC-associated PCB congeners depended on the PC size (Figures 3 and S4). The average PCB congener PSAF for HSL+PC FINE $(0.12 \pm 0.03)$ exceeded that for HSL+PC MEDIUM $(0.010 \pm 0.005)$ by 12 times and that for HSL+PC ${ }_{\text {COARSE }}(0.018 \pm 0.009)$ and by 7 times. The average PCB congener PSAF for HSL+PC ${ }_{\text {COARSE }}$ exceeded that for HSL+PC MEDIUM $_{\text {by } 1.7}$ times. Statistical analysis showed significant differences between HSL+PC $C_{M E D I U M}$ and HSL+PC FINE but no differences between $\mathrm{HSL}+\mathrm{PC}_{\mathrm{MEDIUM}}$ and $\mathrm{HSL}+\mathrm{PC} \mathrm{C}_{\mathrm{COARSE}}$ for all congeners (Figure S4).

The higher PSAF for $\mathrm{HSL}+\mathrm{PC}_{\text {COARSE }}$ than for $\mathrm{HSL}+\mathrm{PC}_{\text {MEDIUM }}$ may be attributed to underestimation of sediment concentrations because of the more heterogeneous and variable distribution of PC in the HSL+PC COARSE sediment (Figure 1) discussed above. Because of this source of uncertainty, $\mathrm{HSL}+\mathrm{PC} \mathrm{COARSE}_{\text {Was not compared with HSL in Figure } 3 .}$

The concentration of PCB congeners in the PS remained relatively unchanged (i.e., not statistically different) during increasing mixing periods (Figure S5). The absence of a substantive change in PCB concentrations in the PS with longer mixing times demonstrated that equilibrium (or near-equilibrium) among matrices (i.e., PC, sediment, and PS) was achieved within $60 \mathrm{~d}$ of mixing.

\section{Bioavailability evaluation using a historically contaminated sediment amended with PC}

The MH sediment had a markedly different homolog group profile compared to PCB-containing PC. The $\mathrm{MH}$ sediment had much higher proportional concentrations of mono-, di- and tri-chlorobiphenyls but lower proportional concentrations of penta-, hexa- and hepta-chlorobiphenyls (Figure S6). Some of the congeners that were relatively abundant in the $\mathrm{MH}$ sediment were present only at very low concentrations or were non-detect in the PC. These congeners will be referred to as "sediment-only-PCBs", and the most abundant ones are shown in Figure 4. PCB congeners present in PC and also present in the $\mathrm{MH}$ sediment will be referred to as "sediment + PC PCBs" and are also shown in Figure 4. 
For some of the PCBs present in PC (i.e., 121/95/88, 101/90, 99, 97, 111, 110, 149, 118, 153, 132, 105, 138,158 , and 128), their relative abundance in the $\mathrm{MH}$ sediment was much lower than in PCB-containing PC (Figure S7). Therefore, it was expected that for those congeners adding PC to the MH sediment would result in the bulk of the mass present being associated with the $\mathrm{PC}$ as opposed to the MH sediment and enable apportionment in bioavailability between the two sources of PCBs (PC vs MH sediment). This expectation was met for a number of congeners, as shown in Figure S7. For thirteen analytes, the average concentration in the sediment more than doubled when $\mathrm{PC}$ was added to $\mathrm{MH}$ sediment $\left(\mathrm{MH}+\mathrm{PC} \mathrm{FINE}_{\mathrm{F}}\right.$ treatment), indicating that for those congeners $50 \%$ or more of the bulk PCB mass for that treatment was derived from the $\mathrm{PC}$ allowing comparison of their bioavailability with the bioavailability of native congeners measured for the in $\mathrm{MH}$ sediment, for which $100 \%$ of the mass was sourced from sediment particles.

Addition of $\mathrm{PC}$ to the $\mathrm{MH}$ sediment resulted in a $41 \%$ increase in the bulk concentration of $\Sigma \mathrm{PCBs}$ in $\mathrm{MH}+\mathrm{PC}_{\mathrm{FINE}}$ relative to $\mathrm{MH}$ but resulted in varying increases in congener-specific average concentrations (Figure S8). The percent increases were highest for congeners that were scarce in the sediment but prominent in the PC (Figure S7). The percent increase (from 1 to 303\%) in bulk concentration resulting from amending the historically contaminated $\mathrm{MH}$ sediment with $\mathrm{PC}$ was much higher than the percent increase for the PS (from 0 to 101\%), which has been shown to be a good thermodynamic metric for bioavailability assessment (e.g., Smedes et al. 2017).

The overall impact of adding PC to the MH sediment is illustrated by comparing the PSAF for $\mathrm{MH}$ and $\mathrm{MH}+\mathrm{PC}_{\mathrm{FINE}}$ (Figure 5). For PCB congeners, when the measured bulk sediment concentration increased by over $100 \%$ (2-fold) from the presence of PC, the PSAF decreased by up to $55 \%$ (Figure 5). The effect of $\mathrm{PC}$ addition on the bioavailable fraction of sediment associated PCBs in $\mathrm{MH}$ was also evaluated. For congeners that were relatively abundant in the $\mathrm{MH}$ sediment but were virtually absent from $\mathrm{PC}$ (i.e., sediment-only-PCBs), the PSAF were typically lower for $\mathrm{MH}+\mathrm{PC}_{\mathrm{FINE}}$ by 1 to $4 \%$ (but not significantly) than for $\mathrm{MH}$, indicating no change in bioavailability of native PCBs in the presence of PC (Figure S9).

\section{Differential Bioavailability}

Due to differences in bulk sediment concentrations of the various treatments used in the present study as well as differences in $\mathrm{OC}$ for the HSL and MH sediments in the sediment, bioavailable fraction comparisons among the $\mathrm{HSL}, \mathrm{MH}, \mathrm{MH}+\mathrm{PC}_{\mathrm{FINE}}$ and $\mathrm{HSL}+\mathrm{PC}_{\mathrm{MEDIUM}}$ treatments are best achieved by comparing PSAFs. For congeners shown in Figure 6, the average PCB congener PSAF for MH $(0.41 \pm$ $0.14)$ was similar to the average PSAF for HSL $(0.56 \pm 0.14)$, but PSAF values for MH were on average 3.5 times higher than those for HSL+PC ${ }_{F I N E}(0.12 \pm 0.02)$ and 49 time higher than those for $\mathrm{HSL}+\mathrm{PC}_{\text {MEDIUM }}(0.009 \pm 0.003)$. Even greater differences were obtained for PSAF values between HSL

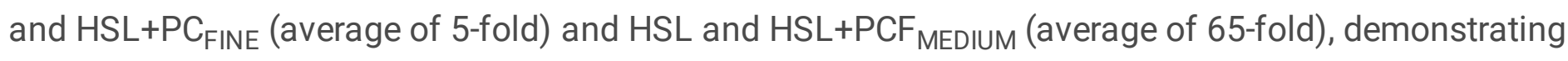
lower bioavailability for PCBs derived from PC dispersed in sediment compared to PCBs sorbed to sediments obtained from field sites and much more so for medium size fraction PC. Statistical analysis showed no significant differences between non-PC treatments (i.e., HSL and MH) for all congeners except 
for congener $147 / 149$ and 153 . The $\mathrm{MH}$ treatment was significantly different from $\mathrm{HSL}+\mathrm{PC}_{\text {MEDIUM }}$ for all

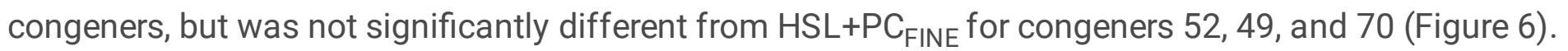
Statistical differences among HSL, HSL+PC $C_{\text {FINE }}$ and $\mathrm{HSL}+\mathrm{PC}_{\text {MEDIUM }}$ are best illustrated in Figure 3.

\section{Discussion}

To the authors' knowledge, the present study is the first addressing the bioavailability for PCB-containing PC dispersed in sediment. Bioavailability of PCB from PC in sediment was successfully measured using ex situ passive sampling, which provides reliable estimates of potential for benthic bioaccumulation. Virtually unchanged PS concentrations of PCBs after 60, 119 and $158 \mathrm{~d}$ confirmed effective equilibrium conditions between the PC + sediment matrix and PS at 60 d indicating that desorption of PCBs from PC approached a plateau after $60 \mathrm{~d}$ of mixing with sediment.

PC size had a strong effect on the bioavailable fraction after $60 \mathrm{~d}$ of sediment and PC mixing, as $H S L+P C_{F I N E}$ generated $\Sigma P C B$ s equilibrium average concentration in the PS 12 -fold higher than for HSL+PC MEDIUM $_{\text {and } 15 \text {-fold higher than for HSL+PC }}$ COARSE. Therefore, particles in the range of 0.25 to $5 \mathrm{~mm}$ resulted in over one order of magnitude less accumulation in the PS compared to the $<0.045 \mathrm{~mm}$ fraction. Such a magnitude of difference was expected as surface-area-to-volume ratio for the fine PC was approximately 6 times higher than for the medium PC and approximately 5 times higher relative to the coarse particles, and the desorption rate of PCBs from paint is expected to increase with decreasing particles sizes and increasing surface area. The average concentration in the PS for the coarse fraction was similar to that for the medium fraction as expected based on the similar surface-area-to-volume ratio for those size fractions. Although the relation between desorption or bioavailability and particle size has not been previously evaluated for organic contaminants associated with PC, such as trend has been reported for copper associated with PC (Turner et al. 2008). Desorption of PCB associated with PE and polypropylene particles also decreased with increasing surface-area-to-volume ratio (Endo et al. 2013; Lee et al. 2018). The relation between surface-area-to-volume ratio and bioavailability is likely explained by faster desorption rate for surface PCBs than subsurface PCBs in PC.

Because the accumulation in the PS did not increase with longer mixing times, nearly all of the PCBs mass desorption from the fine size paint particles was assumed to have occurred within $60 \mathrm{~d}$. This observation is consistent with the substantial decrease of the rate of release of PCBs from PC in water after day 21 of a leaching study (Uhler et al. in 2021). Because that leaching study used PC mechanically reduced to a size that would pass through a $9.5 \mathrm{~mm}$ standard sieve, desorption of PCBs from medium and coarse PC used in this study was expected to be fairly slow after $60 \mathrm{~d}$. Therefore, larger size fractions would not be expected to exceed the bioavailability of the fine particle sizes if mixed for longer periods.

No published data on the particle-size distribution specifically for PCB-containing paint particles in sediment was found during this research, however particle size data have been generated for other antifouling paint particles sampled from harbors and vessel maintenance sites (USEPA 1979). The 1979

Page 12/24 
EPA study aimed in part in characterizing discharges of effluents and solids from shipbuilding and repair operations characterized particle sizes of sandblasting grit and PC. Sieve analysis of that sandblasting debris indicated that $95 \%$ of the debris-including PC-were sand-sized and retained by a number 40 sieve (i.e. were larger than $0.42 \mathrm{~mm}$ ). Sediment samples taken from two estuaries in southwest UK were examined for APPs. The majority of suspected spent APPs were in the size range 0.5 to $1 \mathrm{~mm}$ (MullerKaranassos et al. 2019). For sediment samples collected from a fishery base in Guangdong Province of South China, the highest concentrations of paint-related biocide occurred in coarse-size fraction ( 0.2 to 2 $\mathrm{mm}$ ) sediments from near the boat maintenance facilities (Wu et al. 2016), which the authors attributed to a high density of biocide-containing PC. Based on this literature information, spent paint particles in sediments originating from harbors and vessel maintenance sites appear to primarily occur in $>0.2-\mathrm{mm}$ size class which correspond to the medium size PC used in the present study.

Investigation of differential bioavailability is essential for understanding environmental fate and for evaluation environmental risks associated with the contaminated anthropogenic matrices present in sediments (Beckingham and Ghosh 2017). The differential bioavailability potential between HSL (all PCB mass associated with sediment particles) and HSL+PC treatments ( 99.5\% of PCB mass associated with PC) is illustrated in Figure 3. For the congeners shown in Figure 3, the PSAF for HSL exceeded that for HSL+PC FINE $_{\text {on average by } 5 \text { times and that for HSL+PC }}$ MEDIUM by 62 times. Differential

bioavailability was also evaluated using sediment from $\mathrm{MH}$ with a much higher mass of PCBs associated with sediment particles compared to HSL sediment (Figure 6). Despite orders on magnitude differences in sediment PCBs concentration, the PSAF for MH were similar than those for HSL. The PSAF for those sediments represent the bioavailable fraction for PCBs associated with sediments as an additional point of comparison for sediment-amended paint-chips-associated PCBs (Figure 6). The PSAF for MH was 3.5 times higher for $\mathrm{MH}$ than for $\mathrm{HSL}+\mathrm{PC}_{\mathrm{FINE}}$ and 47 times than for $\mathrm{HSL}+\mathrm{PC}_{\text {MEDIUM }}$ for the sum of the most abundant congeners in PC. Furthermore, addition of fine PC to $\mathrm{MH}$ sediment caused a $30 \%$ overall decrease in PSAF for PC-PCBs as indicated by comparing the averages for $\mathrm{MH}+\mathrm{PC}_{\mathrm{FINE}}$ and $\mathrm{MH}$ (Figure 5). To our knowledge, this is the first study using PSAF for comparing bioavailability potential. The PSAF is analogous to the biota-sediment-accumulation factor (BSAF) and are therefore useful to compare bioavailability potential across sediments with widely different bulk concentrations and different types and concentrations of sorptive matrices such as organic. Similar to higher BSAF indicating higher bioavailability potential relative to bulk sediment concentration when comparing sediments, higher PSAF indicates higher bioavailability potential.

The results from the present study indicate that PC act as a strong sorptive matrix for PCBs. In a related study of the leaching of PCBs from PC, Uhler et al. (2021) reported that more $99 \%$ of the PCBs in the PCBpaint chips remained trapped in the paint matrix at the cessation of leaching after 1,150 days (i.e., less than $1 \%$ of the PCB mass desorbed into the water). This finding is highly indicative of much stronger sorption of PCBs to PC than to sediment, as over $50 \%$ of the PCBs desorbed from suspended sediments from contaminated sites in the USA (i.e., Hunters Point Naval Shipyard, Lake Hartwell and Hudson River) over a periods ranging from days to weeks (Carroll et al. 1994; Zimmerman et al. 2004; Werner et al. 
2005). A proposed mechanism that explains the observed partitioning behavior of PCBs from PCB PC is a process where surface bound $\mathrm{PCB}$ molecules partition relatively rapidly into water in contact with the paint chips; the rate of desorption decreases as the PCB molecules on the paint surface become depleted. Ultimately, the majority of the PCBs have slow matrix diffusion out of the PC and into the surrounding water. According to this proposed mechanism, PCBs partitioning from PC into overlying or porewater is thus inherently limited to a very small fraction of the total PC PCBs mass that is located at the surface of the PC. During the PC and sediment mixing in the present study (for up to 159 days), PCBs were desorbing from pre-loaded PC into the surrounding pore water and resorbing to the clean sediment matrix. Slow desorption of PCBs from PC (especially for particles in the range of 0.25 to $5 \mathrm{~mm}$ ), relative to desorption from the sediment matrix would explain the results obtained in the present study. Slow desorption of DDT and its major transformation products from PC as a result of strong sorption for those compounds to that matrix has also been shown, as less than $10 \%$ of the total mass of those compounds desorbed to water within $7 \mathrm{~d}$ under active mixing (Wu et al 2016). Desorption rates are expected to be lower under low mixing in situ conditions.

The differential bioavailability results generated in the present study demonstrate the much lower bioavailability for PC-PCBs relative to native PCBs historically associated with sediment particles. This is especially relevant considering that regulators are increasingly recognizing the value of bioavailabilitybased assessment of contaminated sites for management decisions (Greenberg et al. 2014; Booij et al. 2016). Information from this study on the bioavailability of PCBs from PC will allow environmental scientists to assess the potential environmental effects of PCB-containing paint chips in areas where their release to the environment has occurred. Differential bioavailability information is expected to be particularly relevant for use in risk assessment and remediation decision making for areas where sediment contaminated with PCB originating from sources other than PC are co-located with PCB PC, such as the Swan Island Lagoon, located in the Portland Harbor (OR, USA) (Oregon Department of Environmental Quality 2020) and many other sites (Supplementary Information). To our knowledge, this is the first study investigating differential bioavailability for paint or other manufactured product containing hydrophobic organic chemicals added as an ingredient during manufacturing. The research framework provided in the present study are also applicable for investigating the differential bioavailability of contaminants associated with other manufactured materials which have been found in sediment and soil such as DDT-containing paint (Lin et al. 2009; Wu et al. 2016) and PCB-containing materials such as plaster and caulk (Andersson et al. 2004; Russ et al. 2006; Herrick et al. 2007; Davies and Delistraty 2016)

\section{Conclusion}

PCB were used as performance additives to paint formulations between the 1940s and early 1970s. Despite reports of sediment and soil contamination by PCB-containing PC at multiple field sites, no known previous scientific study evaluating the bioavailability potential of PCB-containing PC in aquatic environments exist. This study comparatively evaluated the bioavailability potential of PCB-containing PC dispersed in sediments with no know PCB impact (HSL sediments) and in with sediments with 
historical PCB impacts from non-paint sources ( $\mathrm{MH}$ sediments). PC size had a strong effect on the bioavailable PCB fraction, as fine particles $(<0.045 \mathrm{~mm})$ generated $\sum$ PCBs concentration in the PS over one order of magnitude higher than for coarser particles $(0.25-5 \mathrm{~mm})$, which has been shown to be the prevalent PC fraction dispersed into environment as a result of vessel maintenance activities. Differential bioavailability was successfully assessed using PSAF, a novel approach that is analogous BSAF, but simpler to apply because of the many complexities associated measuring bioaccumulation. The PSAF for the historically contaminated MH sediments were $~ 50-60$ times higher than those for the $0.25-5 \mathrm{~mm}$ PC mixed in non-PCB impacted HSL sediments. This indicates much lower bioavailability for PCBs associated with PC compared to bioavailability from sediment historically contaminated with PCBs from non-paint sources. Forensic investigations have made it clear that sites have multiple sources of PCBs (including and excluding PC). This study shows that bioavailability of PCBs from sources such as PC present in sediment is not directly proportional to the bulk phase concentrations.

\section{Declarations}

\section{Acknowledgments}

The present study was funded by ExxonMobil Environmental and Property Solution Company via a cooperative agreement between ERDC and Newfields, Inc. Citation of trade names used in the paper does not constitute an official endorsement or approval of the use of such commercial products. The results interpretations contained herein are the views of the author and are not to be construed as official views of the Department of the Army or the Department of Defense. This manuscript was approved for public release by the Chief of Engineers.

Funding: The present study was funded by ExxonMobil Environmental and Property Solution Company via a cooperative agreement between US Army Engineer Research and Development Center and Newfields, Inc.

\section{Conflicts of interest/Competing interests: Not applicable}

Availability of data and material: Data are available from the corresponding author (guilherme.lotufo@usace.army.mil).

Code availability: Not applicable

\section{References}

1. Adams RG, Lohmann R, Fernandez LA, MacFarlane JK, Gschwend PM (2007) Polyethylene devices: Passive samplers for measuring dissolved hydrophobic organic compounds in aquatic environments. Environmental Science Technology 41(4):1317-1323.

https://doi.org/10.1021/es0621593 
2. Andersen A, Bjornbom E, Sverud T (2000) Decommissioning of ships - Environmental standards. Shipbreaking practices/onsite assessment Bangladesh, Chittagong. Oslo, Norway: Det Norske Veritas. https://shipbreakingplatform.org/wp-content/uploads/2018/11/dnvbangladesh.pdf

3. Andersson M, Ottesen RT, Volden T (2004) Building materials as a source of PCB pollution in Bergen, Norway. Sci Total Environ 325(1-3):139-144. https://doi.org/10.1016/j.scitotenv.2003.11.014

4. Apell JN, Gschwend PM (2016) In situ passive sampling of sediments in the Lower Duwamish Waterway Superfund site: Replicability, comparison with ex situ measurements, and use of data. Environ Pollut 218:95-101. https://doi.org/10.1016/j.envpol.2016.08.023

5. Beckingham B, Ghosh U (2017) Differential bioavailability of polychlorinated biphenyls associated with environmental particles: Microplastic in comparison to wood, coal and biochar. Environ Pollut 220:150-158. https://doi.org/10.1016/j.envpol.2016.09.033

6. Bellucci LG, Cassin D, Giuliani S, Botter M, Zonta R (2016) Sediment pollution and dynamic in the Mar Piccolo of Taranto (southern Italy): insights from bottom sediment traps and surficial sediments. Environ Sci Pollut Res 23(13):12554-12565. https://doi.org/10.1007/s11356-016-6738-6

7. Booij K, Robinson CD, Burgess RM, Mayer P, Roberts CA, Ahrens L, Allan IJ, Brant J, Jones L, Kraus UR, Larsen MM (2016) Passive sampling in regulatory chemical monitoring of nonpolar organic compounds in the aquatic environment. Environmental Science Technology 50(1):3-17. https://doi.org/10.1021/acs.est.5b04050

8. Carroll KM, Harkness MR, Bracco AA, Balcarcel RR (1994) Application of a permeant/polymer diffusional model to the desorption of polychlorinated biphenyls from Hudson River sediments. Environmental Science Technology 28(2):253-258. https://doi.org/10.1021/es00001a041

9. Davies H, Delistraty D (2016) Evaluation of PCB sources and releases for identifying priorities to reduce PCBs in Washington state (USA). Environ Sci Pollut Res 23(3):2033-2041. https://doi.org/10.1007/s11356-015-4828-5

10. Davies H, Delistraty D (2016) Evaluation of PCB sources and releases for identifying priorities to reduce PCBs in Washington state (USA). Environ Sci Pollut Res 23(3):2033-2041. https://doi.org/10.1007/s11356-015-4828-5

11. Du S, Wall SJ, Cacia D, Rodenburg LA (2009) Passive air sampling for polychlorinated biphenyls in the Philadelphia metropolitan area. Environmental Science Technology 43(5):1287-1292. https://doi.org/10.1021/es802957y

12. Endo S, Yuyama M, Takada H (2013) Desorption kinetics of hydrophobic organic contaminants from marine plastic pellets. Mar Pollut Bull 74(1):125-131. https://doi.org/10.1016/j.marpolbul.2013.07.018

13. Endo S, Yoshimura M, Kumata H, Uchida M, Yabuki Y, Nakata H (2020) Reduced bioavailability of polycyclic aromatic hydrocarbons (PAHs) in sediments impacted by carbon manufacturing plant effluent: Evaluation by ex situ passive sampling method. Environ Pollut 256:113448. https://doi.org/10.1016/j.envpol.2019.113448 
14. Greenberg MS, Chapman PM, Allan IJ, Anderson KA, Apitz SE, Beegan C, Bridges TS, Brown SS, Cargill IV, McCulloch JG, M.C. and Menzie CA (2014) Passive sampling methods for contaminated sediments: Risk assessment and management. Integrated Environmental Assessment Management 10(2):224-236. https://doi.org/10.1002/ieam.1511

15. Gschwend PM, MacFarlane JK, Reible DD, Lu X, Hawthorne SB, Nakles DV, Thompson T (2011) Comparison of polymeric samplers for accurately assessing PCBs in pore waters. Environ Toxicol Chem 30(6):1288-1296. https://doi.org/10.1002/etc.510

16. Gustavson K (2014) PCB content of sediments collected at the Manistique Harbor, Michigan. ERDC Technical Notes Collection (ERDC/EL TN-14-2). Vicksburg, MS: U.S. Army Engineer Research and Development Center. https://apps.dtic.mil/sti/citations/ADA602790

17. Herrick RF, Lefkowitz DJ, Weymouth GA (2007) Soil contamination from PCB-containing buildings. Environ Health Perspect 115(2):173-175. https://doi.org/10.1289/ehp.9646

18. Jartun M, Ottesen RT, Steinnes E, Volden T (2009) Painted surfaces-Important sources of polychlorinated biphenyls (PCBs) contamination to the urban and marine environment. Environ Pollut 157(1):295-302. https://doi.org/10.1016/j.envpol.2008.06.036

19. Jensen S, Renberg L, Olsson M (1972) PCB contamination from boat bottom paint and levels of PCB in plankton outside a polluted area. Nature 240(5380):358-360. https://doi.org/10.1038/240358b0

20. Johnsen A, Engøy T, 2000. Contamination from Marine Paints-A Norwegian Perspective. Defense Technical Information Center Compilation Part Notice ADP010602. Part of report: Approaches to the implementation of Environment Pollution Prevention Technologies at Military Bases. https://apps.dtic.mil/sti/citations/ADP010602Joyce AS, Portis LM, Parks AN, Burgess RM, 2016. Evaluating the relationship between equilibrium passive sampler uptake and aquatic organism bioaccumulation. Environmental Science \& Technology 50(21), 11437-11451. https://doi.org/10.1021/acs.est.6b03273

21. Kojima R, Kobayashi S, Satuito CGP, Katsuyama I, Ando H, Seki Y, Senda T (2016) A method for evaluating the efficacy of antifouling paints using Mytilus galloprovincialis in the laboratory in a flow-through system. PloS One 11(12):e0168172. https://doi.org/10.1371/journal.pone.0168172

22. Lee H, Byun DE, Kim JM, Kwon JH (2018) Desorption of hydrophobic organic chemicals from fragment-type microplastics. Ocean Science Journal 53(4):631-639. https://doi.org/10.1007/s12601-018-0051-x

23. Lin T, Hu Z, Zhang G, Li X, Xu W, Tang J, Li J (2009) Levels and mass burden of DDTs in sediments from fishing harbors: the importance of DDT-containing antifouling paint to the coastal environment of China. Environmental Science Technology 43(21):8033-8038. https://doi.org/10.1016/j.envpol.2016.09.033

24. Lohmann R, Booij K, Smedes F, Vrana B (2012) Use of passive sampling devices for monitoring and compliance checking of POP concentrations in water. Environ Sci Pollut Res 19(6):1885-1895. https://doi.org/10.1007/s11356-012-0748-9 
25. Martin ME, Richards MJ (2010) PCB and heavy metal soil remediation, former boat yard, South Dartmouth, Massachusetts. Proceedings of the Annual International Conference on Soils, Sediments, Water and Energy, Worcester, MA. https://scholarworks.umass.edu/soilsproceedings/vol14/iss1/19

26. Miller S (1983) The PCB imbroglio. Environmental Science Technology 17(1):11A. https://doi.org/10.1021/es00107a717

27. Muller-Karanassos C, Turner A, Arundel W, Vance T, Lindeque PK, Cole M (2019) Antifouling paint particles in intertidal estuarine sediments from southwest England and their ingestion by the harbour ragworm, Hediste diversicolor. Environ Pollut 249:163-170. https://doi.org/10.1016/j.envpol.2019.03.009

28. Oregon Department of Environmental Quality (2020) Environmental Cleanup Site Information (ECSI) Database Site Summary Report - Details for Site ID 271, Swan Island Upland Facility/Vigor Industrial. https://www.deq.state.or.us/lq/ECSI/ecsidetail.asp?seqnbr=271

29. Pennel K (2016) Specific Surface area. In: Reference module in earth system and environmental sciences. Elsevier Inc. DOI:10.1016/B978-0-12-409548-9.09583-X

30. Ruus A, Green NW, Maage A, Skei J (2006) PCB-containing paint and plaster caused extreme PCBconcentrations in biota from the Sørfjord (Western Norway)-A case study. Marine pollution Bulletin 52(1):100-103. https://doi.org/10.1016/j.marpolbul.2005.11.010

31. Scott M, Snyder R (2015) PCBs in construction materials: old chemical, new context. Environmental Claims Journal 27(3):244-263. https://doi.org/10.1080/10406026.2015.1062660

32. Schmidt SN, Burgess RM (2020) Evaluating polymeric sampling as a tool for predicting the bioaccumulation of polychlorinated biphenyls by fish and shellfish. Environmental Science Technology 54(16):9729-9741. https://doi.org/10.1021/acs.est.9b07292

33. Smedes F, Rusina TP, Beeltje H, Mayer P (2017) Partitioning of hydrophobic organic contaminants between polymer and lipids for two silicones and low density polyethylene. Chemosphere 186:948957. https://doi.org/10.1016/j.chemosphere.2017.08.044

34. Turner A, Fitzer S, Glegg GA (2008) Impacts of boat paint chips on the distribution and availability of copper in an English ria. Environ Pollut 151(1):176-181.

https://doi.org/10.1016/j.envpol.2007.02.007

35. Uhler AD, Hardestine J, Edwards DA, Lotufo GR (2021) Leaching rate of polychlorinated biphenyls (PCBs) from marine paint chips. Published online. https://doi.org/10.1007/s00244-021-00868-6

36. Environmental PA (1979) Development Document for Proposed Effluent Limitations Guidelines and Standards for the Shipbuilding and Repair. Point Source Category (Draft). Effluent Guidelines Division, Office of Water and Hazardous Materials, Washington DC. https://nepis.epa.gov/Exe/ZyPDF.cgi/00000SLB.PDF?Dockey=00000SLB.PDF

37. Werner D, Higgins CP, Luthy RG (2005) The sequestration of PCBs in Lake Hartwell sediment with activated carbon. Water Res 39(10):2105-2113. https://doi.org/10.1016/j.watres.2005.03.019

38. Wolska L, Mechlińska A, Rogowska J, Namieśnik J (2014) Polychlorinated biphenyls (PCBs) in bottom sediments: Identification of sources. Chemosphere 111:151-156. 
https://doi.org/10.1016/j.chemosphere.2014.03.025

39. Wu CC, Bao LJ, Tao S, Zeng EY (2016) Significance of antifouling paint flakes to the distribution of dichlorodiphenyltrichloroethanes (DDTs) in estuarine sediment. Environ Pollut 210:253-260. https://doi.org/10.1016/j.envpol.2015.12.012

40. Zimmerman JR, Ghosh U, Millward RN, Bridges TS, Luthy RG (2004) Addition of carbon sorbents to reduce $\mathrm{PCB}$ and $\mathrm{PAH}$ bioavailability in marine sediments: Physicochemical tests. Environmental Science Technology 38(20):5458-5464. https://doi.org/10.1021/es034992v

\section{Figures}

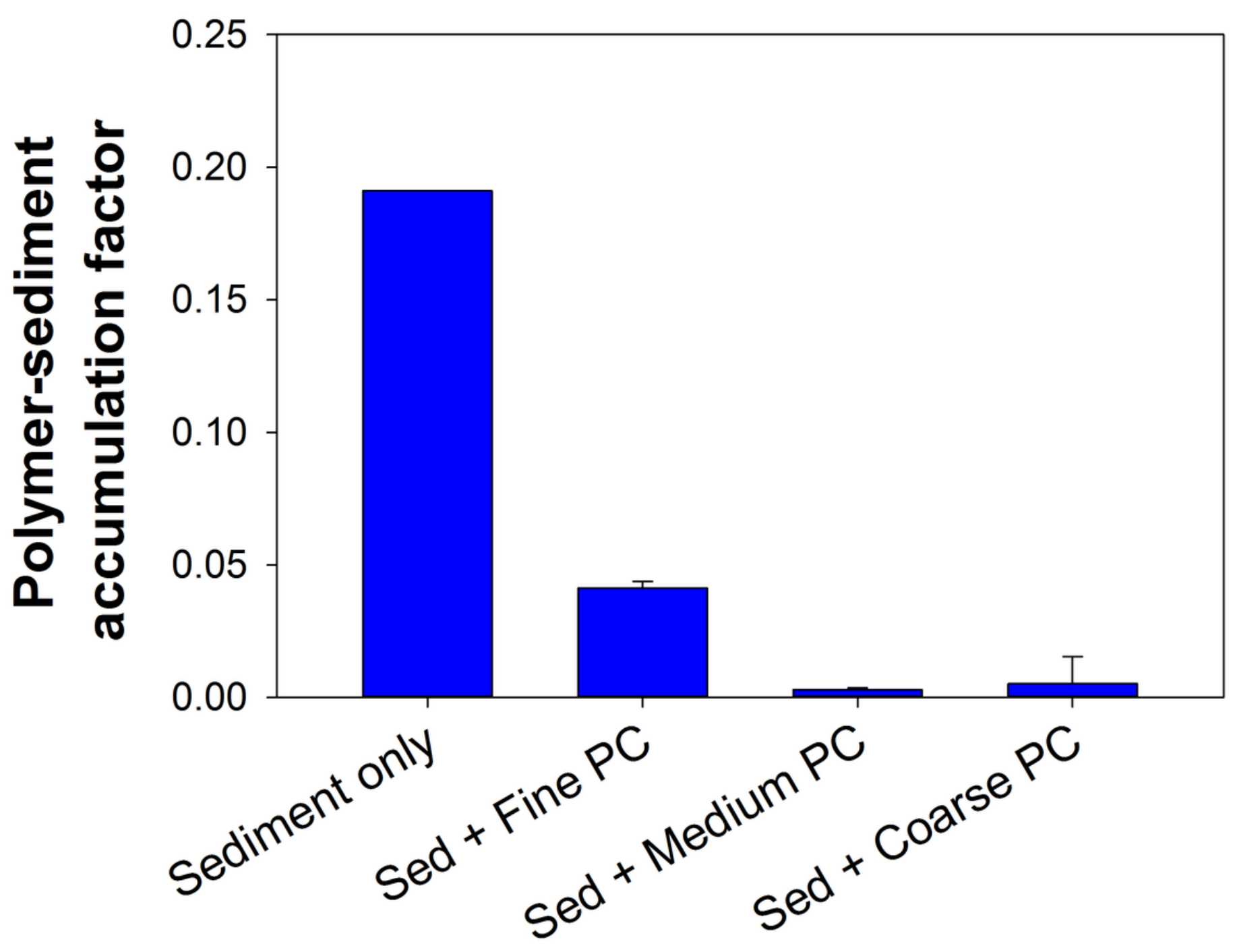

Figure 1 
Average ( \pm 1 standard deviation, $n=4)$ concentration of $\Sigma$ PCBs in bulk sediment $(A)$ and in PS $(B)$ following ex situ passive sampling for HSL sediment and HSL amended with PCB-containing PC (fine, medium or coarse particle sizes).

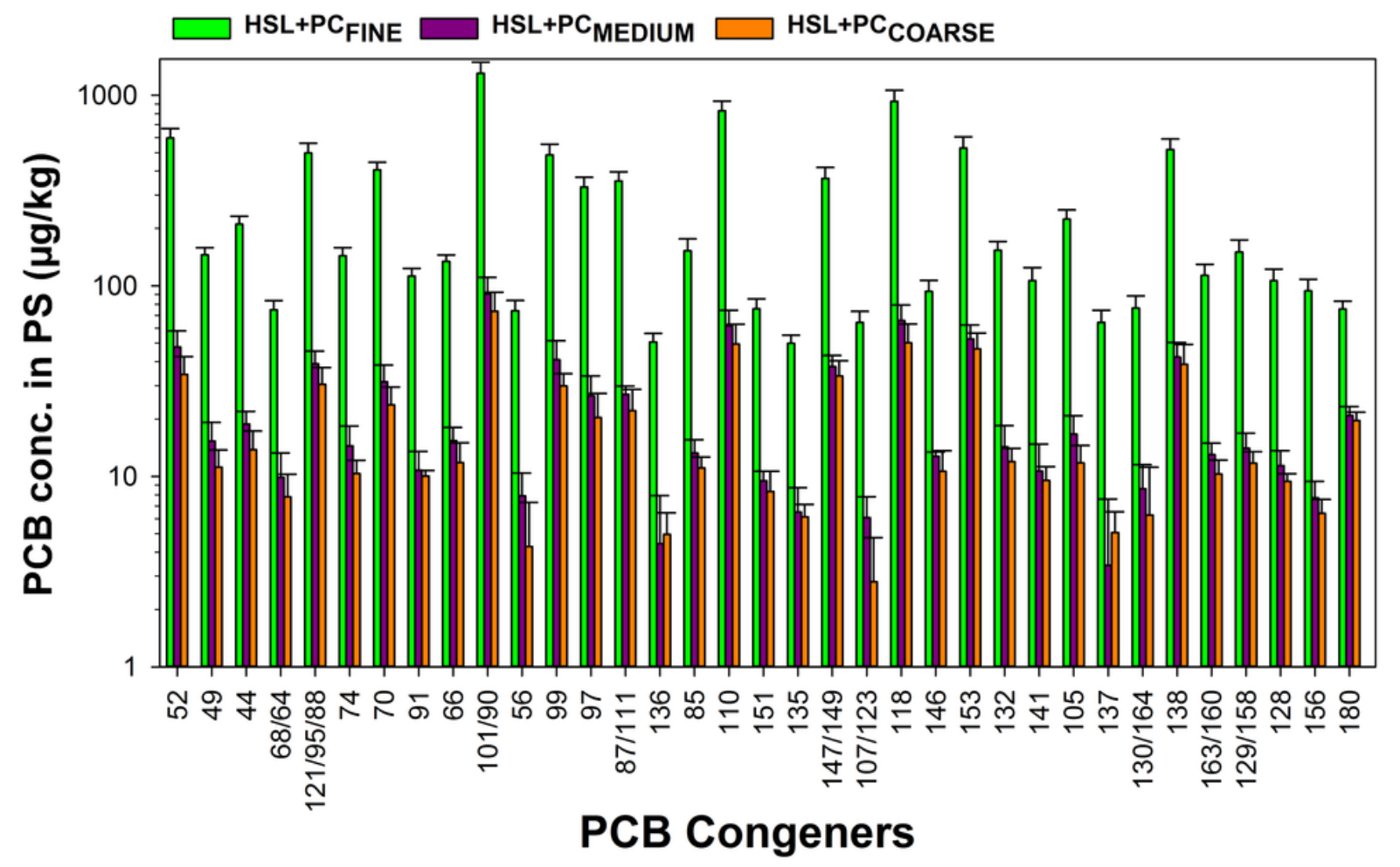

Figure 2

Average ( \pm 1 standard deviation, $n=4$ ) concentration of PCB congeners in the PS following mixing with HSL sediment amended with fine (HSL+PCFINE), medium (HSL+PCMEDIUM) or coarse (HSL+PCCOARSE) PCB-containing PC. Analytes contributing $<0.5 \%$ to the $\Sigma$ PCBs concentration were omitted for visual simplicity. 


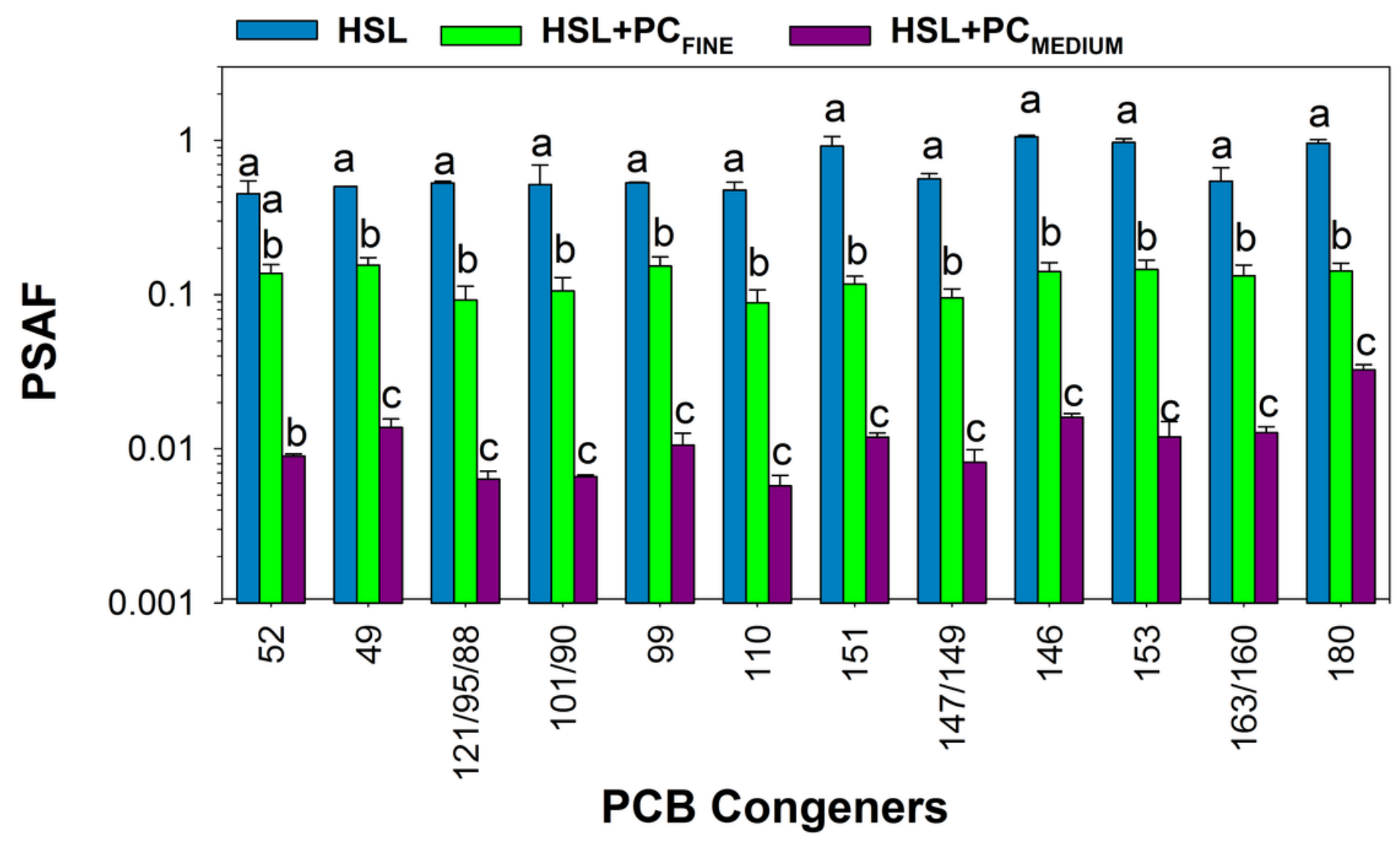

Figure 3

Average ( \pm 1 standard deviation, $n=4)$ PSAF for HSL sediment and HSL amended with fine (HSL+PCFINE) or medium (HSL+PCMEDIUM) PCB-containing PC. Analytes are the only ones detected in all treatments. Treatments that share the same letters are not significantly different from each other when analyzed using pairwise comparisons. 


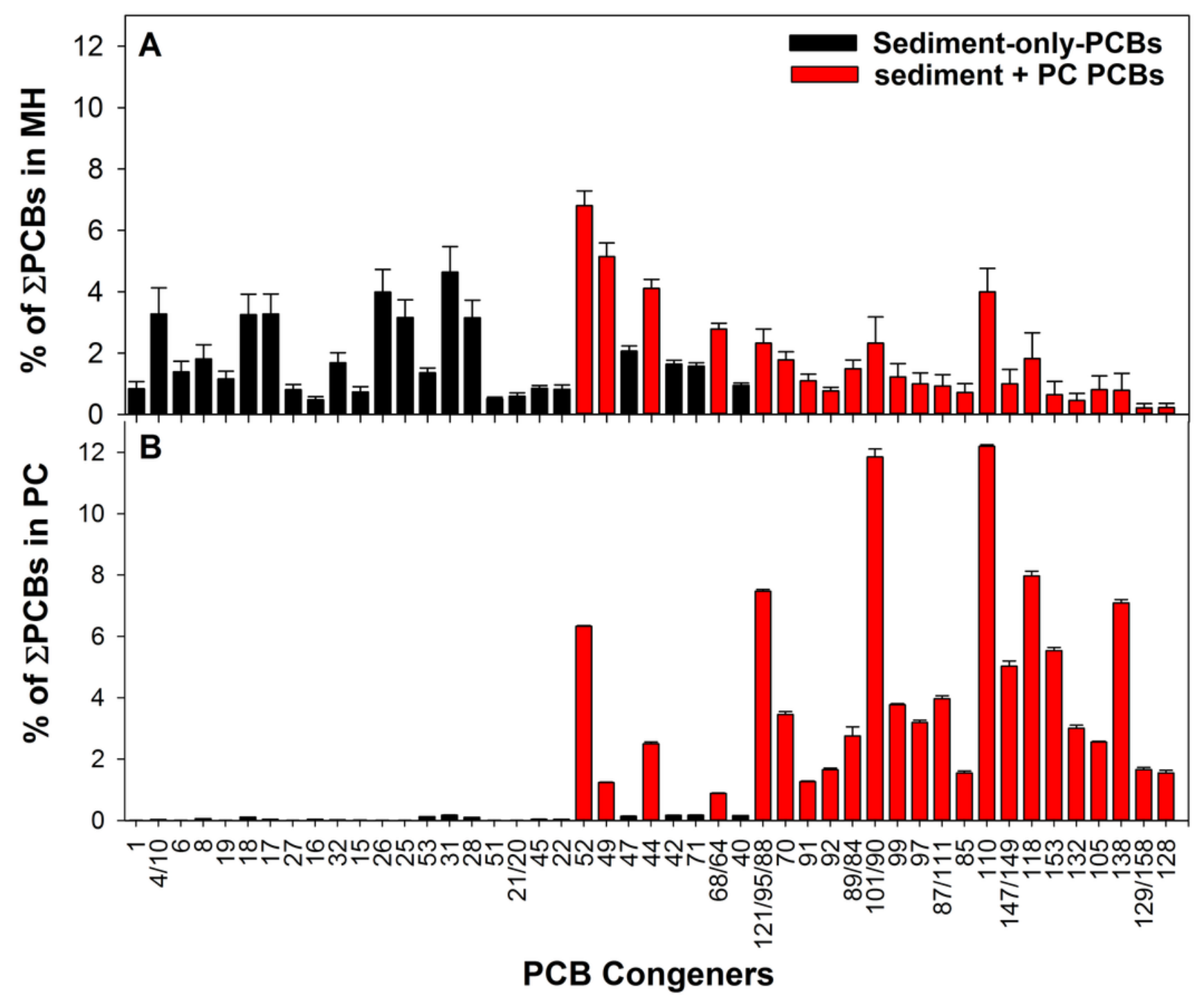

Figure 4

PCB congener profiles for $\mathrm{MH}$ sediment $(\mathrm{A})$ and for $\mathrm{PC}(\mathrm{B})$ for select analytes. The average $( \pm 1$ standard deviation, $n=4$ ) percent contribution of each analyte was derived by dividing its concentration by the $\Sigma \mathrm{PCB}$ concentration. Congeners that were relatively abundant in the $\mathrm{MH}$ sediment but were present only at very low concentrations or non-detects in the PC (referred to as "sediment-only-PCBs"), are shown in black. Analytes present in both $\mathrm{MH}$. 


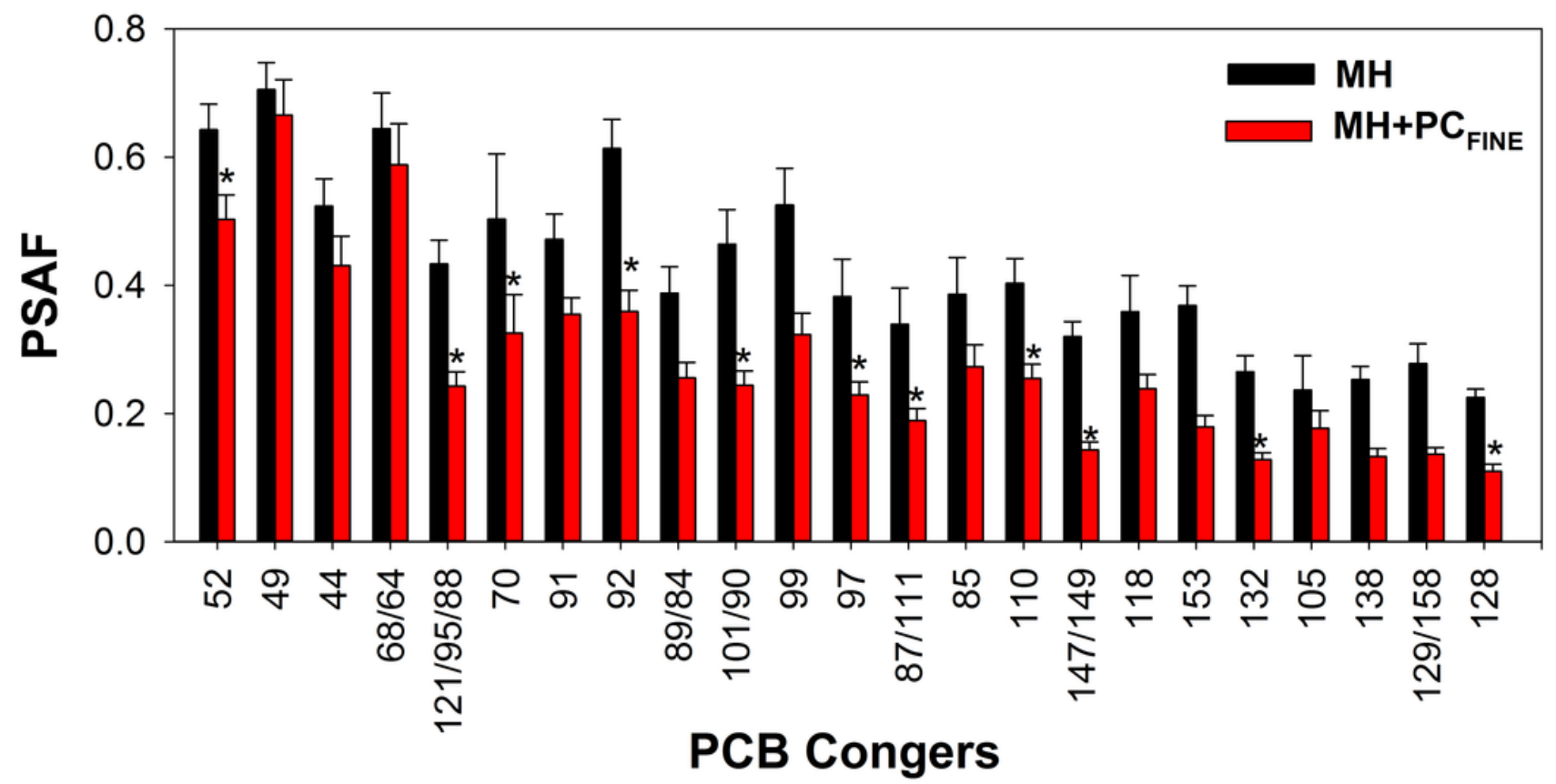

Figure 5

Average ( \pm 1 standard deviation) PSAF following ex situ passive sampling for the $\mathrm{MH}$ and $\mathrm{MH}+\mathrm{PCFINE}$. Analytes are those corresponding to the red bars in Figure 4. Asterisk $\left(^{*}\right)$ indicates significant difference between treatments.

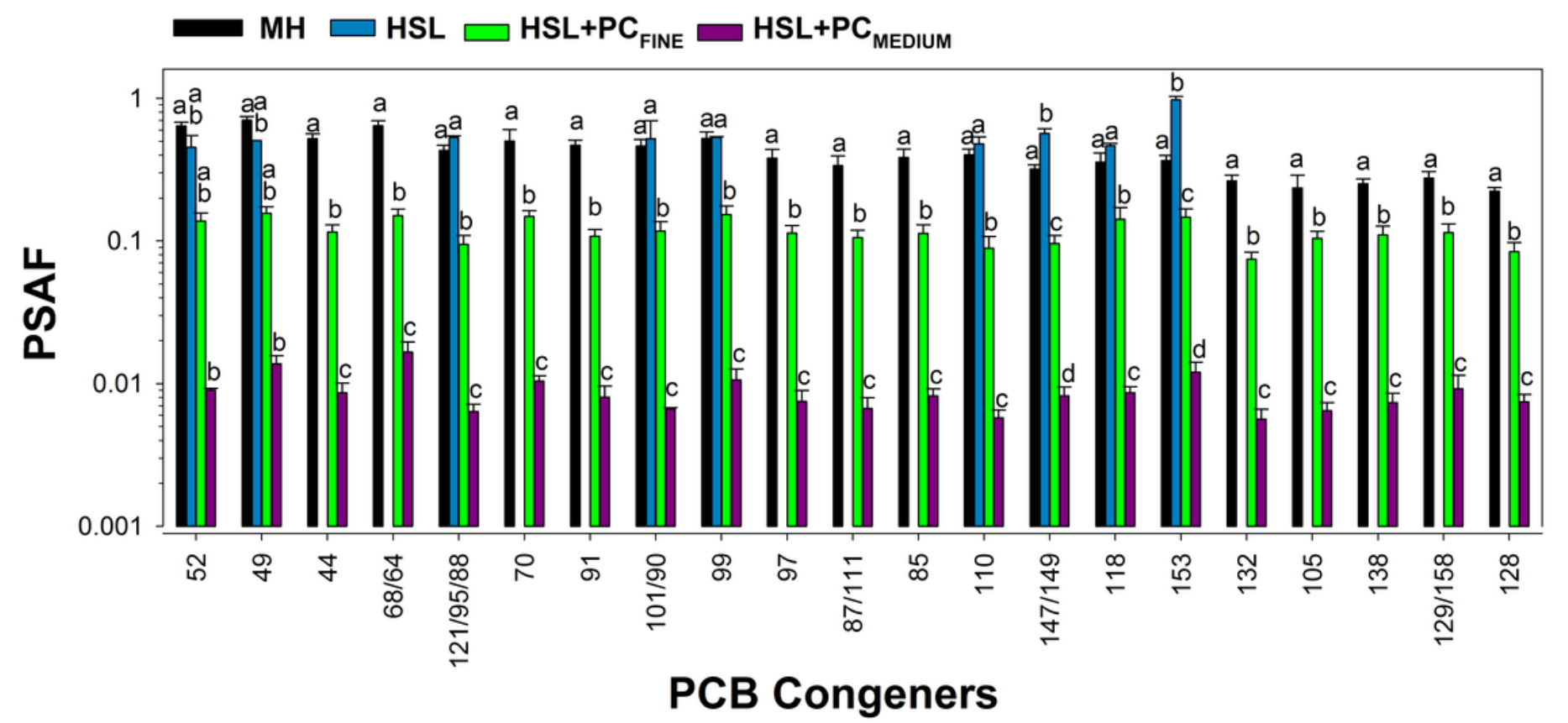

Figure 6

Average PSAF following ex situ passive sampling for HSL, MH and for PCB-containing fine PC amended sediment (HSL+PCFINE and HSL+PCMEDIUM) treatments. Analytes are those corresponding to red bars 
in Figure 4 with PCBs 84, 89 and 92 omitted because of analytical interference in HSL + PC. Treatments that share the same letters are not significantly different from each other when analyzed using pairwise comparisons.

\section{Supplementary Files}

This is a list of supplementary files associated with this preprint. Click to download.

- SupplementallnformationQAQC.xlsx

- Supplementarylnformation.docx 